\title{
Low birth weight associates with glomerular area in young male lgA nephropathy patients
}

\author{
Paschal Ruggajo ${ }^{1,2^{*}}$, Sabine Leh ${ }^{2,4}$, Einar Svarstad ${ }^{2,3}$, Hans-Peter Marti' ${ }^{2,3}$ and Bjørn Egil Vikse ${ }^{2,5}$
}

\begin{abstract}
Background: In a recent study we demonstrated that low birth weight (LBW) was associated with increased risk of progressive IgA nephropathy (IgAN). In the present study we investigate whether this could be explained by differences in glomerular morphological parameters.

Methods: The Medical Birth Registry of Norway has registered all births since 1967 and the Norwegian Kidney Biopsy Registry has registered all kidney biopsies since 1988. Patients diagnosed with IgAN, registered birth weight and estimated glomerular filtration rate above $60 \mathrm{ml} / \mathrm{min} / 1.73 \mathrm{~m}^{2}$ at time of diagnosis were eligible for inclusion. Patients were included in a case-control manner based on whether or not they had LBW or were small for gestational age (SGA). Glomerular area, volume and density were measured using high resolution digital images and differences were compared between groups.

Results: We included 51 IgAN patients with a mean age of 23.6 years, $47.1 \%$ male. Compared to IgAN patients without LBW or SGA, IgAN patients with LBW and/or SGA had larger glomerular area (16,235 \pm 3744 vs 14,036 \pm $3502 \mu^{2}, p$-value 0.04). This was significant for total cohort and male but not female. On separate analysis by

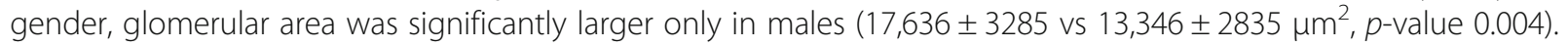
Glomerular density was not different between groups. In adjusted linear regression analysis, glomerular area was negatively associated with birth weight.
\end{abstract}

Conclusion: Among young adult IgAN patients, low birth weight is associated with having larger glomerular area, especially in males. Larger glomeruli may be a sign of congenital nephron deficit that may explain the increased risk of progressive IgAN.

\section{Background}

Brenner and co-workers suggested that adverse intrauterine environment, for example due to placental insufficiency or maternal undernutrition, was associated with impaired nephron development and increased risk of hypertension and progressive kidney disease in adult life [1]. Birthweight related parameters such as low birth weight (LBW) and small for gestational age (SGA) are strong surrogate markers for adverse intrauterine environment $[2,3]$. LBW has been associated with increased risk of hypertension [4], albuminuria [5, 6] and progressive

\footnotetext{
* Correspondence: prugajo@yahoo.com

${ }^{1}$ Department of Internal Medicine, Muhimbili University of Health and Allied Sciences (MUHAS), P.O.Box 65001, Dar es Salaam, Tanzania

2Department of Clinical Medicine, University of Bergen, Bergen, Norway

Full list of author information is available at the end of the article
}

chronic kidney disease $[7,8]$. Fewer studies have investigated effects of SGA, but in a previous study from Norway we showed that SGA was a stronger risk marker than LBW for development of ESRD in adult age [9].

IgA nephropathy (IgAN) is the most frequent primary idiopathic glomerulonephritis worldwide [10-12] and has a variable clinical course [13-15]. In a previous study we showed that LBW and SGA were risk factors for progression to ESRD in IgAN patients [16].

Several previous autopsy-based stereological and histomorphometric studies have reported strong correlations between LBW and reduced glomerular numbers as well as increased glomerular volume [17-19]. A previous study has also shown that IgAN patients born SGA had increased risk for glomerulosclerosis and arterial hypertension [20]. To our knowledge, the association between 
birth weight and glomerular histomorphometric changes among IgAN patients has not been investigated before.

In the present study we aimed to investigate how LBW and SGA in IgAN patients associate with specific glomerular morphological changes compared to IgAN without LBW and SGA. We hypothesized that LBW and SGA would be associated with fewer and larger glomeruli in line with the Brenner hypothesis but that the effects of LBW and SGA could be different. In our previous study cited above, associations were stronger in males, so gender differences were also investigated in the present study.

\section{Methods}

\section{Description of registries}

Since 1967, the Medical Birth Registry of Norway has registered extensive medical data on all births in Norway (total population of 5.1 million) [21]. The Norwegian Kidney Biopsy Registry has registered clinical and histopathological data (including diagnosis) for all patients who have had a kidney biopsy performed in Norway since 1988. Since 1980, the Norwegian Renal Registry has registered data on all patients in Norway who developed ESRD (defined as starting maintenance dialysis treatment or undergoing renal transplantation). The data from all registries were available until December 2013 and data were linked using the unique 11-digit national identification number.

The regional ethics committee of Western Norway gave clearance for the study (2013/553), participants were asked for consent by mail.

\section{Variables from the medical birth registry and Norwegian kidney biopsy registry}

LBW was defined as birth weight less than the 10th percentile for gender (2930 g for male, $2690 \mathrm{~g}$ for female) in the study population of our previous study [16]. From 1967 through 1998, gestational age was based on the last menstrual period and from 1999 onwards on routine ultrasonographic examination in gestational weeks 17 through 20. Based on national data on birth weight, gestational week, gender and plurality, a z-score denoting numbers of standard deviations from mean of birth weight for each week of gestational age was calculated for all cases and controls based on data from the Medical Birth Registry [22, 23]. Small for gestational age (SGA) was defined as birth weight less than the 10th percentile for gestational week in the study population of our previous study [16] (defined by z-score less than -1.2900 for male and -1.5280 for female gender). Preterm birth was defined as a gestational age less than 37 weeks [22, 23].

Maternal pregestational disease was defined as maternal rheumatic disease, renal disease, diabetes mellitus or hypertension diagnosed before pregnancy and reported at birth to the Medical Birth Registry [24]. Maternal pre-eclampsia was defined based on the 1972 recommendations of the American College of Obstetricians and Gynecologists, i.e. hypertension and proteinuria after week 20 of gestation [25].

The following clinical variables at the time of kidney biopsy were used in the present study; estimated glomerular filtration rate (eGFR), calculated using the IDMStraceable CKD-EPI equation [26]. All patients were assumed to be of Caucasian race. For patients who had a kidney biopsy performed before year 2005, their serum creatinine levels were reduced by $5 \%$ to standardize them to IDMS-traceable levels [27]. To avoid spurious eGFR distribution in patients with very low values of serum creatinine, all eGFR values exceeding $150 \mathrm{ml} /$ $\mathrm{min} / 1.73 \mathrm{~m}^{2}$ were set to $150 \mathrm{ml} / \mathrm{min} / 1.73 \mathrm{~m}^{2}$. Proteinuria (grams/24 h), systolic and diastolic blood pressure measurements $(\mathrm{mmHg})$ at time of biopsy were all used as continuous variables.

\section{Selection of cases and controls}

We selected cases and controls from patients registered in the described registries (Additional file 1: Figure S1). Eligible patients had registered birth weight, eGFR $>60 \mathrm{ml} / \mathrm{min} / 1.73 \mathrm{~m}^{2}$ at time of biopsy and did not develop ESRD during follow-up (as registered in the Norwegian Renal Registry). The last two criteria were chosen to ensure that during selection, our study population comprised of patients with lowest risk of progressive IgAN population at the time of biopsy (in addition, only 1 eligible patient had developed ESRD). Power calculations were based on extrapolations from two human studies which had published measurements of glomerular size in relation to birth weight $[17,18]$. From these eligible patients, we selected 5 groups of patients:(1) 20 patients randomly selected out of the 230 eligible patients registered in the Kidney Biopsy Registry with a diagnosis of IgAN and being neither LBW nor SGA, (2) all 13 patients with LBW but not SGA, (3) all 15 patients with SGA but not LBW and (4) all 14 patients with both LBW and SGA. As some of the selected patients did not have available kidney biopsy tissue, we were able to include $18,11,10$ and 12 case patients in these respective groups. In addition, (5) we selected 20 patients who were neither LBW nor SGA, had normal findings on kidney biopsy (indicated for proteinuria or haematuria) and had eGFR > $60 \mathrm{ml} / \mathrm{min} / 1.73 \mathrm{~m}^{2}$ as normal controls; this control group was age-and-sex matched with the group of IgAN cases without LBW or SGA; 19 patients in this control group had available tissue and were included.

\section{Histopathological and histomorphometric variables}

Representative periodic acid Schiff stained $3 \mu \mathrm{m}$ thick sections from paraffin embedded formalin fixed tissue 
were used. Morphological evaluation was done on digital slides scanned at $40 \mathrm{x}$ resulting in a resolution of $0.25 \mu \mathrm{m}$ per pixel (Aperio ScanScope ${ }^{\mathrm{Tw}}$ XT System, 1360 Park Center Drive Vista, CA 92081, USA). The digital images were viewed in Imagescope (version 12, Leica/ Aperio). We recorded the total number of glomeruli, the number of glomeruli with mesangial hypercellularity, endocapillary hypercellularity, global sclerosis, segmental sclerosis and tubular atrophy as defined by the Oxford classification for IgAN and a MEST score was calculated [28]. The annotation pen tool was used to measure glomerular tuft areas and cortical area of each profile. We determined the glomerular density as a ratio of number of glomeruli per cortical area, and this was calculated for all glomeruli (reported as total glomerular density), for sclerosed glomeruli and for non-sclerosed glomeruli. We used total glomerular density during analysis. The glomerular tuft area was defined as an area bound by outer capillary loops of the glomerular tuft and the mean glomerular area was obtained by averaging the area of all eligible glomeruli in the profile. Glomerular diameter (d) was calculated from the formula $d=$ square root of $(4 \mathrm{~A} / \pi)$, where $A=$ glomerular area and $\pi=3.142$, assuming the glomerular tuft to be circular in shape.

For estimating glomerular volume we used the WeibelGomez formula expressed as $\mathrm{GV}=(\mathrm{GA})^{3 / 2} \mathrm{x} \beta / \mathrm{d}$; where $\mathrm{GV}=$ glomerular volume, $\mathrm{GA}=$ glomerular tuft area, $\beta=$ 1.38 (assuming the glomerulus is spherical in shape) and $d$ is a size distribution coefficient that is used to adjust for the variation in glomerular size; we used $d=1.01$ as adopted from other studies [29-31]. The microscopic and morphometric evaluations for all kidney biopsies in this study were performed by the first author after thorough training by an experienced nephropathologist (second author) who also verified all measurements. These evaluations were blinded for information on LBW / SGA.

\section{Statistical analysis}

Birth weight related parameters were used as exposure variables whereas histopathological and histomorphometric parameters were used as outcome variables. In the primary analyses, outcome variables were compared between the four sub-groups with IgAN described above; in further analyses all groups with LBW and/or SGA were combined. Also, IgAN patients without LBW or SGA were compared to control patients. Continuous variables were tested for normal distribution (confirmed by P-P plots for all glomerular size parameters) and compared using student $\mathrm{t}$-tests while categorical variables were compared using Chi-square tests. Linear regression statistics were used to determine the association between glomerular area and birthweight-related variables and clinical variables. In the primary analysis (model 1 ) we adjusted for diagnostic group (IgA nephropathy vs control) as the study sample consisted of these two separate groups. In the secondary analysis (model 2) we further adjusted for gender and age at biopsy. If not otherwise stated, values are reported as mean \pm standard deviation; $P<0.05$ was considered statistically significant, and all tests were 2 tailed. Analyses were performed using the SPSS version 21 (SPSS, Chicago, IL).

\section{Results}

A total of 51 patients with IgAN were included in the present study, of these $24(47.1 \%)$ were males. Mean age at biopsy was 23.6 years and mean eGFR was $95.3 \mathrm{ml} /$ $\mathrm{min} / 1.73 \mathrm{~m}^{2}$. At the time of kidney biopsy, patients without LBW or SGA had comparable clinical characteristics to patients with LBW and/or SGA (Table 1). As expected, birth weight characteristics varied between groups.

\section{Birth weight related variables and glomerular morphological changes}

As shown in Table 2, glomerular measurements and other morphological variables were similar between groups with LBW and/or SGA (explored with t-tests between groups), these groups were therefore combined in the main analysis. Glomerular morphology, as investigated with markers of glomerular damage and the Oxford classification, were similar between groups. In glomerular histomorphometric analysis, compared to IgAN patients without LBW or SGA, IgAN patients with LBW and/or SGA had larger glomerular area $\left(16,235 \pm 3744\right.$ vs $14,036 \pm 3502 \mu \mathrm{m}^{2}, p$-value $0.004)$. Further analyses stratified by gender showed that glomerular area was significantly larger only in males $\left(17,636 \pm 3285\right.$ vs $13,346 \pm 2835 \mu^{2}$, p-value 0.004$)$ but not in females $\left(14,588 \pm 4018\right.$ vs $14,918 \pm 3758 \mu \mathrm{m}^{2}$, p-value 0.8$)$. Glomerular density was not different between groups. In a sensitivity analysis, we tested whether including only patients with 9 glomeruli or more [32] would change the results for glomerular area, in these analyses the differences in glomerular area were comparable, but due to a lower $\mathrm{N}$ it did not reach statistical significance. In an analysis in which the two groups with LBW (excluding the group with only SGA) were compared to the group without LBW and SGA, glomerular area was statistically significantly different $\left(14,036 \mathrm{vs} 16,383 \mu \mathrm{m}^{2}, p\right.$-value 0.04$)$.

\section{Comparison between patients with normal biopsy and IgAN}

To investigate whether development of IgAN altered glomerular area, we compared results for patients with IgAN who did not have LBW or SGA $(N=18)$ to a matched group of control patients with normal biopsies $(N=19)$. As shown in Table 3, clinical characteristics were comparable between these two groups except for proteinuria which was significantly higher among the IgAN controls $(1.8 \pm 1.7$ vs $0.32 \pm 0.28 \mathrm{~g} / \mathrm{d}, p$-value $0.002)$. There were no significant differences between 
Table 1 Cohort characteristics among Cases and Controls in Norway, 1988-2013

\begin{tabular}{|c|c|c|c|c|c|}
\hline & \multirow{2}{*}{$\begin{array}{l}\text { IgAN controls } \\
\text { Neither LBW nor SGA }\end{array}$} & \multicolumn{3}{|l|}{ IgAN cases } & \multirow{2}{*}{$\begin{array}{l}\text { IgAN cases combinec } \\
\text { LBW and/or SGA }\end{array}$} \\
\hline & & LBW but not SGA & SGA but not LBW & Both LBW and SGA & \\
\hline N & 18 & 11 & 10 & 12 & 33 \\
\hline N (\%) male & $8(44.4)$ & $5(45.5)$ & $5(50.0)$ & $6(50.0)$ & $16(48.5)$ \\
\hline Age at Biopsy (years) & $22.8 \pm 9.0$ & $21.1 \pm 8.6$ & $22.3 \pm 7.1$ & $28.3 \pm 8.9$ & $24.1 \pm 8.7$ \\
\hline Weight at Biopsy (Kg) & $76.8 \pm 22.6$ & $56.8 \pm 27.9$ & $68.3 \pm 18.6$ & $75.2 \pm 14.3$ & $66.1 \pm 21.8$ \\
\hline Systolic BP (mmHg) & $124.4 \pm 22.9$ & $118.8 \pm 16.2$ & $131.3 \pm 9.8$ & $126.1 \pm 17.5$ & $124.8 \pm 15.6$ \\
\hline Diastolic BP (mmHg) & $76.6 \pm 13.2$ & $72.6 \pm 14.9$ & $77.8 \pm 10.1$ & $72.7 \pm 11.1$ & $74.0 \pm 12.2$ \\
\hline $\mathrm{eGFR}\left(\mathrm{ml} / \mathrm{min} / 1.73 \mathrm{~m}^{2}\right)$ & $94.8 .0 \pm 27.3$ & $99.4 \pm 32.9$ & $95.5 \pm 23.5$ & $92.1 \pm 18.6$ & $95.5 \pm 25.0$ \\
\hline Urinary Protein (g/d) & $1.8 \pm 1.7$ & $1.7 \pm 1.5$ & $1.0 \pm 1.3$ & $2.4 \pm 2.6$ & $1.7 \pm 1.9$ \\
\hline Birth Weight (kg) & $3.6 \pm 0.53$ & $1.9 \pm 0.75^{b}$ & $2.9 \pm 0.17^{a}$ & $2.4 \pm 0.42^{b}$ & $2.4 \pm 0.65^{b}$ \\
\hline Gestational age (week) & $40.3 \pm 1.1$ & $32.6 \pm 4.5^{b}$ & $40.40 \pm 0.70$ & $38.7 \pm 1.2^{b}$ & $37.2 \pm 4.3^{b}$ \\
\hline Birthweight for Gestational Age (Z-score) & $-0.18 \pm 1.04$ & $-0.28 \pm 0.73$ & $-1.56 \pm 0.24^{b}$ & $-2.19 \pm 0.54^{b}$ & $-1.36 \pm 0.98^{b}$ \\
\hline Maternal Pre-eclampsia & $0(0.0)$ & $0(0.0)$ & $2(20.0)$ & $2(16.7)$ & $4(12.1)$ \\
\hline Maternal pregestational disease ${ }^{\mathrm{b}}$ & $0(0.0)$ & $0(0.0)$ & $0(0.0)$ & $1(8.3)$ & $1(3.0)$ \\
\hline
\end{tabular}

${ }^{a}$ pvalue $<0.01,{ }^{b}$ p-value $<0.001$ as compared to IgAN controls

${ }^{\mathrm{b}}$ Maternal pregestational disease was defined as maternal rheumatic disease, renal disease, diabetes mellitus or hypertension

birth weight-related and glomerular histomorphometric characteristics observed between the two groups but there was a non-significant trend towards larger glomeruli in IgAN patients.

\section{Glomerular area against birth weight-related and clinical characteristics}

In order to further analyse the associations we conducted linear regression statistics to investigate associations between glomerular area and birth-weight and clinical variables. In these analyses we included both patients with IgAN and normal controls. Glomerular area was significantly higher in those with low birth weight in the adjusted model 2 analysis (a decrease of $1357 \mu^{2}$ in glomerular area for every $1 \mathrm{~kg}$ increase in birthweight, $p$-value $=0.01$ ) but not in the primary model 1 analysis. Furthermore, maternal pre-eclampsia, gender and age at biopsy were significantly associated with glomerular area

Table 2 Glomerular histopathological and histomorphometric variables stratified by LBW and/or SGA, Norway (1988-2013)

\begin{tabular}{|c|c|c|c|c|c|}
\hline & \multirow{2}{*}{$\begin{array}{l}\text { IgAN Controls } \\
\text { Without } \\
\text { LBW or SGA }\end{array}$} & \multicolumn{3}{|l|}{ IgAN Cases } & \multirow{2}{*}{$\begin{array}{l}\text { IgAN cases combinec } \\
\text { LBW and/or SGA }\end{array}$} \\
\hline & & LBW but not SGA & SGA but not LBW & Both LBW and SGA & \\
\hline N & 18 & 11 & 10 & 12 & 33 \\
\hline N (\%) with M-score of 1 & $10(55.6)$ & $8(72.7)$ & $5(50.0)$ & $4(33.3)$ & $17(51.5)$ \\
\hline N (\%) with E-score of 1 & $3(16.7)$ & $2(18.2)$ & $0(0.0)$ & $1(8.3)$ & $3(9.1)$ \\
\hline $\mathrm{N}(\%)$ with S-score of 1 & $1(5.6)$ & $3(27.3)$ & $2(20.0)$ & $1(8.3)$ & $6(18.2)$ \\
\hline N (\%) with T-score of 1 & $0(0.0)$ & $0(0.0)$ & $0(0.0)$ & $0(0.0)$ & $0(0.0)$ \\
\hline$\%$ of glomeruli with mesangial hypercellularity & $49.6 \pm 27.4$ & $49.1 \pm 35.6$ & $39.8 \pm 21.7$ & $35.0 \pm 29.7$ & $41.2 \pm 29.4$ \\
\hline$\%$ of glomeruli with endocapillary hypercellularity & $0.93 \pm 2.7$ & $7.3 \pm 20.1$ & $0.00 \pm 0.00$ & $2.0 \pm 6.8$ & $3.2 \pm 12.3$ \\
\hline$\%$ of glomeruli with global sclerosis & $3.3 \pm 6.9$ & $12.8 \pm 29.6$ & $3.3 \pm 6.2$ & $2.5 \pm 5.9$ & $5.9 \pm 17.8$ \\
\hline$\%$ of glomeruli with segmental sclerosis & $0.69 \pm 2.9$ & $2.5 \pm 5.2$ & $1.6 \pm 3.3$ & $0.25 \pm 0.85$ & $1.5 \pm 3.6$ \\
\hline \multicolumn{6}{|l|}{ Histomorphometric variables } \\
\hline Number of glomeruli $(\mathrm{N})$ & $14.1 \pm 7.8$ & $16.0 \pm 7.5$ & $16.2 \pm 6.4$ & $14.7 \pm 11.4$ & $15.6 \pm 8.6$ \\
\hline Glomerular tuft volume $\left(\mu \mathrm{m}^{3} \times 10^{6}\right)^{\mathrm{c}}$ & $2.37 \pm 0.82$ & $2.90 \pm 0.97$ & $2.81 \pm 1.13$ & $2.93 \pm 0.89$ & $2.89 \pm 0.96$ \\
\hline Glomerular tuft area $\left(\mu \mathrm{m}^{2}\right)$ & $14,036 \pm 3502$ & $16,311 \pm 3805$ & $15,899 \pm 4335$ & $16,447 \pm 3478$ & $16,235 \pm 3744^{\mathrm{a}}$ \\
\hline Glomerular tuft diameter $(\mu \mathrm{m})^{c}$ & $132.7 .4 \pm 16.8$ & 143.1. \pm 17.5 & $141.1 \pm 19.5$ & $143.9 \pm 15.9$ & $142.8 \pm 17.0^{\mathrm{a}}$ \\
\hline Glomerular density ( $\mathrm{N}$ per $10^{6} \mathrm{\mu m}^{2}$ ) & $2.95 \pm 0.85$ & $3.54 \pm 1.30$ & $3.36 \pm 0.93$ & $2.66 \pm 1.47$ & $3.17 \pm 1.30$ \\
\hline
\end{tabular}

${ }^{a}$ p-value $<0.01,{ }^{b}$-value $<0.001$ as compared to IgAN controls

c Glomerular tuft volume and glomerular tuft diameter was calculated based on the measured glomerular tuft area (as described in detail in the methods section) 
Table 3 Comparison of clinical, birth-related and glomerular histomorphometric characteristics between normal controls and IgAN controls

\begin{tabular}{|c|c|c|c|}
\hline & $\begin{array}{l}\text { Normal } \\
\text { controls }\end{array}$ & $\begin{array}{l}\text { IgAN } \\
\text { controls }\end{array}$ & \\
\hline & $\begin{array}{l}\text { Not LBW } \\
\text { or SGA }\end{array}$ & $\begin{array}{l}\text { Not LBW } \\
\text { or SGA }\end{array}$ & p-value \\
\hline N & 19 & 18 & \\
\hline N (\%) Male & $10(52.6)$ & $8(44.4)$ & 1.0 \\
\hline Age at Biopsy (years) & $21.8 \pm 8.6$ & $22.8 \pm 9.0$ & 0.7 \\
\hline Systolic BP (mmHg) & $114.7 \pm 15.6$ & $124.4 \pm 22.9$ & 0.1 \\
\hline Diastolic BP (mmHg) & $71.3 \pm 13.8$ & $76.6 \pm 13.2$ & 0.2 \\
\hline eGFR $\left(\mathrm{ml} / \mathrm{min} / 1.73 \mathrm{~m}^{2}\right)$ & $92.5 \pm 28.4$ & $94.8 \pm 27.3$ & 0.8 \\
\hline Urinary protein (g/d) & $0.32 \pm 0.28$ & $1.8 \pm 1.7^{\mathrm{a}}$ & 0.002 \\
\hline Birth Weight (kg) & $3.7 \pm 0.5$ & $3.6 \pm 0.5$ & 0.4 \\
\hline Gestational age (week) & $39.9 \pm 1.4$ & $40.3 \pm 1.1$ & 0.3 \\
\hline $\begin{array}{l}\text { Birth weight for } \\
\text { gestational age (Z-score) }\end{array}$ & $0.25 \pm 0.99$ & $-0.18 \pm 1.04$ & 0.2 \\
\hline $\begin{array}{l}\text { Glomerular tuft volume } \\
\left(\mu \mathrm{m}^{3} \times 10^{6}\right)^{c}\end{array}$ & $1.97 \pm 0.77$ & $2.37 \pm 0.82$ & 0.1 \\
\hline $\begin{array}{l}\text { Glomerular tuft } \\
\text { area }\left(\mu \mathrm{m}^{2}\right)\end{array}$ & $12,522 \pm 3410$ & $14,036 \pm 3502$ & 0.1 \\
\hline $\begin{array}{l}\text { Glomerular tuft } \\
\text { diameter }(\mu \mathrm{m})^{c}\end{array}$ & $125.0 \pm 18.2$ & $132.7 \pm 16.8$ & 0.2 \\
\hline $\begin{array}{l}\text { Glomerular Density } \\
\left(\mathrm{N} \text { per } 10^{6} \mathrm{\mu m}^{2}\right)\end{array}$ & $3.29 \pm 1.40$ & $2.96 \pm 0.85$ & 0.4 \\
\hline
\end{tabular}

in both model 1 and 2 analyses, whereas body weight, BMI and eGFR at biopsy associated with glomerular area only in model 1 analysis (Table 4).

In Fig. 1 we show the inverse relationships between glomerular area and birthweight and z-score of birthweight for gestational age. In Fig. 2 we show the inverse relationships between glomerular area and glomerular density and eGFR.

\section{Discussion}

The present study shows that young IgAN patients who were born with LBW and/or SGA had larger glomerular area at time of diagnosis than IgAN patients born with normal birth weight. The association was statistically significant in total cohort and in males. We consider larger glomerular area to be a marker of lower number of total glomeruli and the study thus suggests that larger glomeruli may at least in part, explain the higher risk of progressive renal disease in young IgAN patients with LBW and/or SGA in Norway [16]. Furthermore, considering that our cohort comprised young adults with preserved renal function (low-risk group), our findings may indeed underestimate the importance of this association. LBW and/or SGA may thus represent a basic vulnerability (first hit) among IgAN patients upon which other insults (immunology, hypertension etc. as second hits) may accelerate progressive nephropathy.

As described, LBW and/or SGA were associated with larger glomeruli at time of diagnosis of IgAN. Importantly, this association showed a dose-response correlation between birthweight and glomerular area. Larger glomeruli were also associated with lower eGFR. Previous studies have shown that glomerular size is a sensitive measure of total kidney glomerular number [18] and is proposed to be among the adaptive compensatory glomerular changes for congenital nephron deficit [17, $18,33]$. LBW has also been associated with low nephron number [34] and higher blood pressure [35] as well as microalbuminuria and low glomerular filtration rate in those born very premature and after intrauterine growth

Table 4 Linear associations between glomerular area and birth related and clinical characteristics, Norway (1988-2013)

\begin{tabular}{|c|c|c|c|c|}
\hline & Model $1 \beta$-coefficient ${ }^{a}$ & p-value & Model $2 \beta$-coefficient ${ }^{b}$ & $p$-value \\
\hline Birthweight (Kg) & -1143 & 0.06 & -1357 & 0.01 \\
\hline Gestational age (Weeks) & -141 & 0.3 & -198 & 0.1 \\
\hline Birth weight for gestational age (Z-score) & -711 & 0.08 & -521 & 0.2 \\
\hline Maternal preeclampsia (Yes/No) & 4305 & 0.02 & 3577 & 0.046 \\
\hline Gender (male vs female) & 1736 & 0.05 & 1849 & 0.03 \\
\hline Age at biopsy $(10 \text { years })^{c}$ & 1368 & 0.007 & 1418 & 0.04 \\
\hline Body weight at biopsy $(10 \mathrm{~kg})^{c}$ & 668 & 0.004 & 491 & 0.1 \\
\hline Body mass index at biopsy $\left(\mathrm{kg} / \mathrm{m}^{2}\right)$ & 238 & 0.02 & 141 & 0.6 \\
\hline $\operatorname{eGFR}\left(10 \mathrm{ml} / \mathrm{min} / 1.73 \mathrm{~m}^{2}\right)^{\mathrm{c}}$ & -530 & 0.01 & -297 & 0.1 \\
\hline Systolic BP $(10 \mathrm{mmHg})^{c}$ & 159 & 0.5 & -164 & 0.54 \\
\hline Urinary Protein $(\mathrm{g} / \mathrm{d})$ & 132 & 0.7 & 154 & 0.6 \\
\hline
\end{tabular}

a Model 1 adjusted for IgA nephropathy diagnosis at biopsy

${ }^{\mathrm{b}}$ Model 2 adjusted for IgA nephropathy diagnosis at biopsy, gender and age at biopsy

' Body weight at time of biopsy, eGFR and systolic BP are given per 10 unit increase to give meaningful coefficients, otherwise one unit was used for other variables 


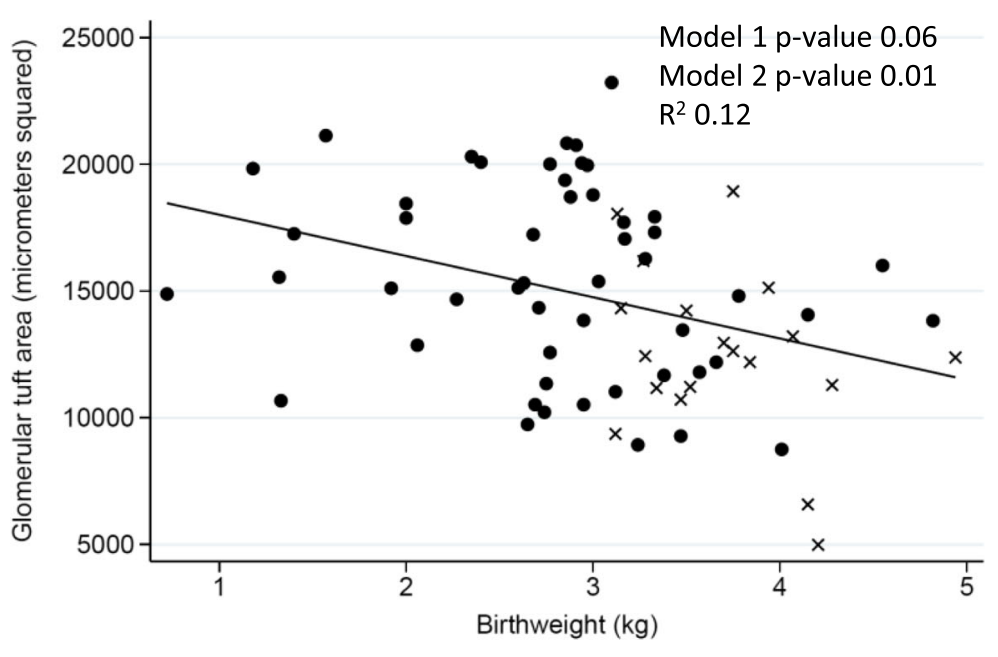

- IgAN patients $\times$ Control patients — Fitted values

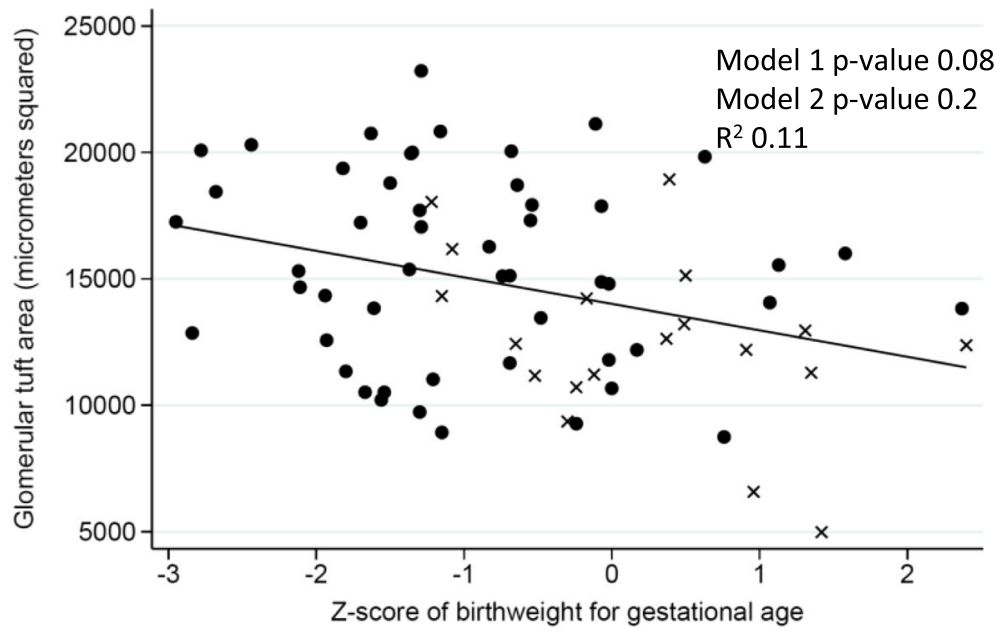

- IgAN patients $\times$ Control patients $\longrightarrow$ Fitted values

Fig. 1 Relationship between Glomerular Area and birthweight and z-score of birthweight for gestational age. Model 1: Analysis adjusted for lgA nephropathy. Model 2: Analysis adjusted for IgA nephropathy, Age and Gender. P-values in figure given for the linear association between the two variables on $\mathrm{x}$-axis and $\mathrm{y}$-axis. Correlation coefficients $\mathrm{R}^{2}$ given for univariate correlation between the two variables on $\mathrm{x}$-axis and $\mathrm{y}$-axis

retardation [36]. In relation to IgAN in particular, a previous study has shown that progressive IgAN is associated with reduced glomerular density and increased glomerular volume [37]. The present study thus links these findings and suggests that LBW and/or SGA increase risk of progressive IgAN, mechanisms might involve lower glomerular number or higher blood pressure $[1,38]$. These mechanisms might be important also in other kidney diseases as we previously have shown that LBW was associated with higher risk of ESRD in general, and also of ESRD due to glomerular disease [7, 39]. In the present study, LBW was defined by the 10th percentile in our previous study and corresponded to $2.93 \mathrm{~kg}$ for men and $2.69 \mathrm{~kg}$ for women [16]. As we observed a dose-response relationship between birth weight and glomerular size, we hypothesize that differences might have been larger if we had used a lower cut-off (WHO definition of LBW is $<2.5 \mathrm{~kg}$ ). Neither LBW alone nor SGA alone were however significantly associated with larger glomeruli in Table 1 and we therefore decided to combine these groups in the remaining analyses. SGA and LBW may however partly be explained by different pathophysiological mechanisms and it is uncertain which is most strongly associated with later development of kidney disease [16]. As differences between groups with LBW and/or SGA in Table 1 were negligible we believe that this is the best approach. It is interesting to note that the group with SGA but not 


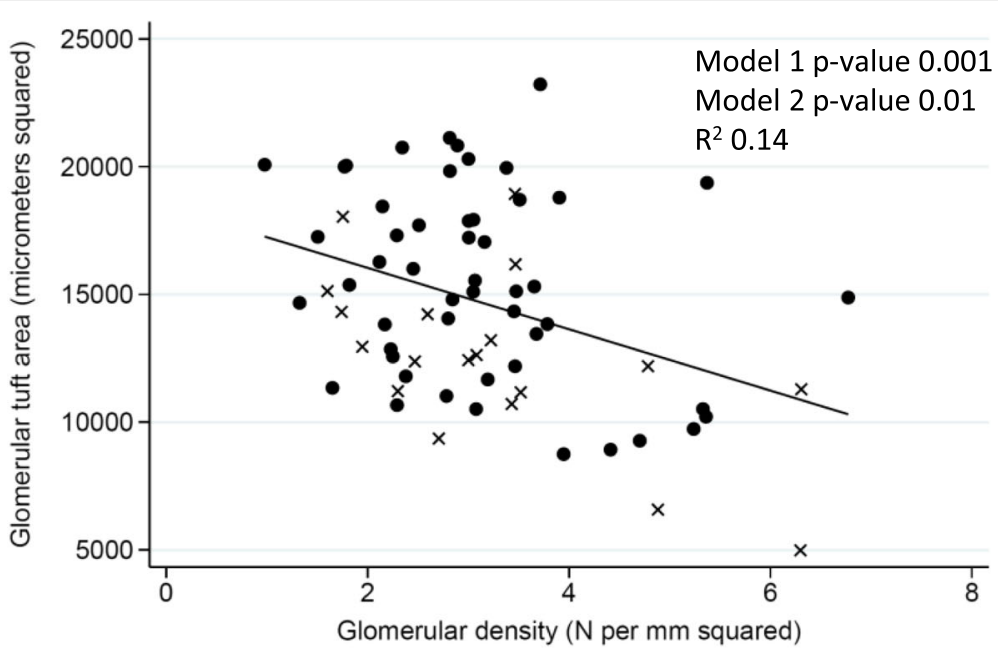

- IgAN patients $\times$ Control patients — Fitted values

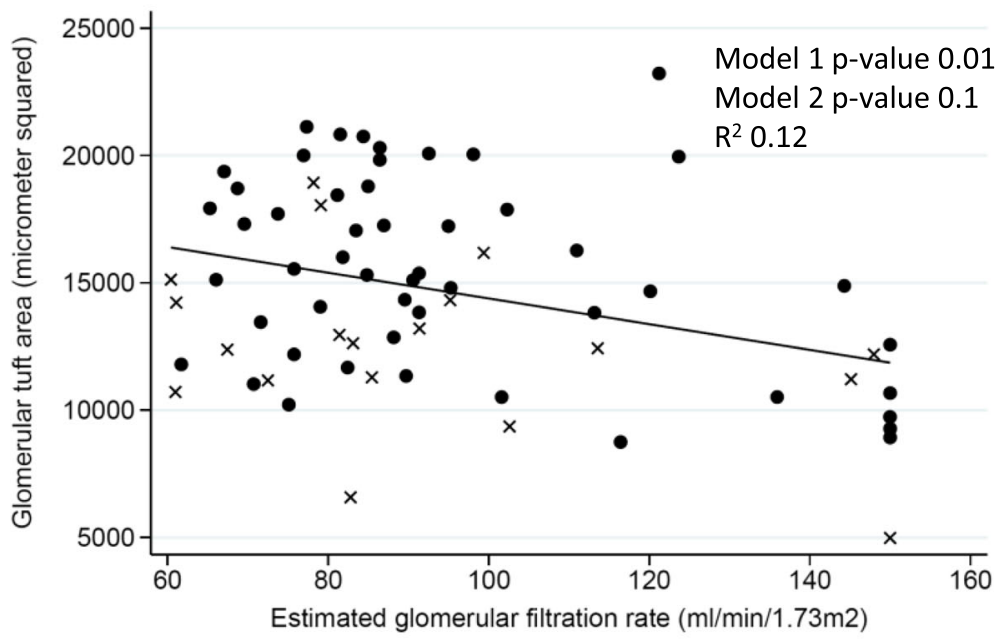

- IgAN patients $\times$ Control patients — Fitted values

Fig. 2 Relationship between Glomerular Area and Glomerular Density and Estimated Glomerular Filtration Rate. Model 1: Analysis adjusted for IgA nephropathy. Model 2: Analysis adjusted for IgA nephropathy, Age and Gender. P-values in figure given for the linear association between the two variables on $\mathrm{x}$-axis and $\mathrm{y}$-axis. Correlation coefficients $\mathrm{R}^{2}$ given for univariate correlation between the two variables on $\mathrm{x}$-axis and $\mathrm{y}$-axis

LBW (mean birth weight of $2.9 \mathrm{~kg}$ ) had nearly the same glomerular area as the groups with LBW (mean birth weights of 1.9 and $2.4 \mathrm{~kg}$ ). It should however be noted that in the comparison of only IgAN patients with vs without LBW (excluding the group with SGA and without LBW), glomerular area was statistically significantly different. Whether birthweight or birthweight for gestational age represents the most powerful predictor of later kidney disease and morphology must be analysed further in future studies.

Brenner postulated that congenital nephron deficit would lead to large glomeruli with glomerular hyperfiltration that would progressively increase risk of glomerular damage. A previous study has reported higher mean percentage of sclerotic glomeruli among IgAN patients who had suffered intra-uterine growth retardation [20]. Further, Ikezumi et al. reported association between LBW and development of focal segmental glomerulosclerosis in children and proposed that this was probably related to glomerular prematurity and podocytopenia [38]. In fact, podocytopenia has been associated with increased disease severity in IgAN [40] and in turn, compensatory podocyte hypertrophy has been associated with progressive glomerulosclerosis [41]. In our paper, there were non-significant trends towards more glomerular sclerosis in those with low birth weight but the degree of glomerular sclerosis 
was mild in our study as we selected patients with preserved kidney function. In our opinion, our study supports the Brenner hypothesis that large glomeruli with hyperfiltration is a link between low birth weight (as a marker of congenital nephron deficit) and progressive kidney disease.

As mentioned above, the association between LBW and larger glomeruli was significant in males but not females. In our previous paper [16] on IgAN, we reported that the association between LBW and ESRD was strong and significant in males but not females. The present study included a slightly higher proportion of female IgAN patients (53\%) as compared to a previous study from the same registry (26\%) [42]. These findings of a possible gender difference are interesting and warrant further investigation to supplement previous human and experimental studies that also have suggested that females might be protected against both progressive nephropathy [43-45] and intrauterine impaired nephron endowment or effects thereof [46].

In adjusted analysis, maternal preeclampsia was associated with a significantly larger glomerular area. Previous studies have shown that pre-eclampsia is associated with placental insufficiency and increases risk of LBW and SGA offspring $[17,47]$. The present study suggests that the associated placental insufficiency might have especially important effects on kidney development. This finding is however limited by the small number of observations in this study (only four patients had a mother with preeclampsia) and should thus be interpreted with caution.

In this study, we report on glomerular morphology from kidney tissue specimens obtained from patients using percutaneous kidney biopsy needle as part of the routine clinical care. This method yields only a limited sample of glomeruli as compared to stereological methods using the physical dissector/fractionator method which is considered as the gold standard. Such stereological methods e.g. Cavalieri, Weibel-Gomez, Maximal Planar Area or Dissector Principle yield accurate estimation for glomerular size and density but are laborious, time consuming, costly and require the whole kidney tissue and are therefore of limited accessibility for routine studies [48, 49]. A previous study has illustrated that reliable mean estimates of glomerular size can be obtained by measuring 9 or more glomeruli; in white patients, measuring fewer than 6 glomeruli reduced the precision [32]. In the present study, even though some patients had fewer than 6 glomeruli, and fewer glomeruli would tend to lower precision of the mean, the glomerular size estimates were statistically significant between groups. Also, results for glomerular area were comparable in a sensitivity analysis where only patients with 9 glomeruli or more were included, although it did not reach statistical significance due to lower N. We would thus argue that estimates of glomerular area could be obtained also by measuring fewer glomeruli in studies with limited number of available patients and tissue.

\section{Conclusion}

In the present study we have shown that among young IgAN patients with preserved renal function, impaired intrauterine growth was associated with larger glomerular area as a sign of congenital nephron deficit. This could in part explain the increased risk of progressive kidney disease in individuals born with LBW or SGA. Further larger studies should investigate why this effect seems to be more important in males than females and in population with higher frequency of offspring birthweight $<2.5 \mathrm{~kg}$. However, the non-significant trend towards larger glomeruli may mean other plausible theories such as pre-diagnosis loss of glomeruli with compensatory hypertrophy may not be ruled out as additional/alternative explanations to what we observe in this study. There seems to be sufficient evidence to argue that consideration of birth weight is an important part of the clinical history of patients with chronic kidney disease.

\section{Strengths}

The strength of this study is that we directly test whether the Brenner hypothesis could explain the increased risk of progressive IgAN that was seen in our previous study [16] and that we test this in IgAN patients with preserved kidney function at an early stage of the disease.

\section{Limitations}

The study is however limited by the fact that percutaneous kidney biopsy method samples only procures a limited number of glomeruli from a small portion of the kidney that may not adequately represent the entire kidney tissue, especially when we consider the fact that glomerular size varies within different kidney regions [50].

\section{Additional file}

Additional file 1: Figure S1. Flowchart for Selection of Cases and Controls. (DOCX 39 kb)

\section{Abbreviations \\ BMI: Body Mass Index; EGFR: Estimated Glomerular Filtration Rate; ESRD: End Stage Renal Disease; GA: Glomerular Tuft Area; GD: Glomerular Density; \\ GV: Glomerular Volume; IDMS: Isotope Dilution Mass Spectrophotometer; IgAN: IgA Nephropathy; LBW: Low Birth Weight; MEST: Mesangial hypercellularity, Endocapillary proliferation, Segmental sclerosis, Tubular atrophy; SGA: Small for Gestational Age; SPSS: Statistical Package for Social Sciences}

\section{Acknowledgements}

We express our sincere gratitude to our study participants.

Further, we thank the Department of Pathology at Haukeland University Hospital in Bergen, Norway.

\section{Availability of data and materials}

The datasets used and/or analysed during the current study are available from the corresponding author on reasonable request. 


\section{Authors' contributions}

PR, BEV and SL conceived the study. PR and SL did data collection and quality check. PR, BEV and SL analysed and interpreted the data and wrote the first draft. ES, HPM and SL reviewed and quality checked the submitted manuscript. All authors read and approved the final manuscript.

\section{Ethics approval and consent to participate}

The regional ethics committee of Western Norway gave clearance for the study (2013/553).

\section{Consent for publication}

The manuscript does not contain individual participant's data.

\section{Competing interests}

The authors declare that they have no competing interests.

\section{Publisher's Note}

Springer Nature remains neutral with regard to jurisdictional claims in published maps and institutional affiliations.

\section{Author details}

${ }^{1}$ Department of Internal Medicine, Muhimbili University of Health and Allied Sciences (MUHAS), P.O.Box 65001, Dar es Salaam, Tanzania. ${ }^{2}$ Department of Clinical Medicine, University of Bergen, Bergen, Norway. ${ }^{3}$ Department of Medicine, Haukeland University Hospital, Bergen, Norway. ${ }^{4}$ Department of Pathology, Haukeland University Hospital, Bergen, Norway. ${ }^{5}$ Department of Medicine, Haugesund Hospital, Haugesund, Norway.

Received: 12 May 2017 Accepted: 5 October 2018 Published online: 22 October 2018

\section{References}

1. Brenner BM, Garcia DL, Anderson S. Glomeruli and blood pressure less of one, more the other? Am J Hypertens. 1988;1(4 1):335-47.

2. Luyckx VA, Brenner BM. Birth weight, malnutrition and kidney-associated outcomes [mdash] a global concern. Nat Rev Nephrol. 2015;11(3):135-49.

3. Lee $A C$, et al. National and regional estimates of term and preterm babies born small for gestational age in 138 low-income and middle-income countries in 2010. Lancet Glob Health. 2013;1(1):e26-36.

4. Mu M, et al. Birth weight and subsequent blood pressure: a meta-analysis. Arch Cardiovasc Dis. 2012;105(2):99-113.

5. Hoy WE, et al. A new dimension to the barker hypothesis: low birthweight and susceptibility to renal disease. Kidney Int. 1999;56(3):1072-7.

6. White SL, et al. Is low birth weight an antecedent of CKD in later life? A systematic review of observational studies. Am J Kidney Dis. 2009;54(2):248-61.

7. Vikse $B E$, et al. Low birth weight increases risk for end-stage renal disease. J Am Soc Nephrol. 2008;19(1):151-7

8. Luyckx VA, et al. A developmental approach to the prevention of hypertension and kidney disease: a report from the low birth weight and nephron number working group. Lancet. 2017;390(10092):424-8.

9. Ruggajo P, et al. Familial factors, low birth weight, and development of ESRD: a nationwide registry study. Am J Kidney Dis. 2016;67(4):601-8.

10. D'amico G. The commonest glomerulonephritis in the world: IgA nephropathy. Qj Med. 1987;64(245):709-27.

11. Floege J, Feehally J. IgA nephropathy: recent developments. J Am Soc Nephrol. 2000;11(12):2395-403.

12. Levy M, Berger J. Worldwide perspective of IgA nephropathy. Am J Kidney Dis. 1988;12(5):340-7.

13. Barbour SJ, Reich HN. Risk stratification of patients with IgA nephropathy. Am J Kidney Dis. 2012;59(6):865-73.

14. Canetta PA, Kiryluk K, Appel GB. Glomerular diseases: emerging tests and therapies for IgA nephropathy. Clin J Am Soc Nephrol. 2014;9(3):617-25.

15. Wyatt RJ, Julian BA. IgA nephropathy. N Engl J Med. 2013;368(25):2402-14.

16. Ruggajo $P$, et al. Low birth weight and risk of progression to end stage renal disease in IgA nephropathy-a retrospective registry-based cohort study. PLoS One. 2016;11(4):e0153819.

17. Manalich $\mathrm{R}$, et al. Relationship between weight at birth and the number and size of renal glomeruli in humans: a histomorphometric study. Kidney Int. 2000;58(2):770-3.
18. Hughson $\mathrm{M}$, et al. Glomerular number and size in autopsy kidneys: the relationship to birth weight. Kidney Int. 2003;63(6):2113-22.

19. Hinchliffe $S$, et al. The effect of intrauterine growth retardation on the development of renal nephrons. BJOG Int J Obstet Gynaecol. 1992;99(4): 296-301.

20. Zidar $\mathrm{N}$, et al. Effect of intrauterine growth retardation on the clinical course and prognosis of IgA glomerulonephritis in children. Nephron. 1998; 79(1):28-32.

21. Irgens LM. The medical birth registry of Norway. Epidemiological research and surveillance throughout 30 years. Acta Obstet Gynecol Scand. 2000; 79(6):435-9.

22. Skjaerven R, GJESSING HK, BAKKETEIG LS. Birthweight by gestational age in Norway. Acta Obstet Gynecol Scand. 2000;79(6):440-9.

23. Glinianaia SV, Skjærven R, Magnus P. Birthweight percentiles by gestational age in multiple births: a population-based study of Norwegian twins and triplets. Acta Obstet Gynecol Scand. 2000;79(6):450-8.

24. Vikse $\mathrm{BE}$, et al. Preeclampsia and the risk of end-stage renal disease. $\mathrm{N}$ Engl J Med. 2008;359(8):800-9.

25. Group, N.H.B.P.E.P.W. Report on high blood pressure in pregnancy (consensus report). Am J Obstet Gynecol. 1990;163:1691-712.

26. Matsushita $\mathrm{K}$, et al. Comparison of risk prediction using the CKD-EPI equation and the MDRD study equation for estimated glomerular filtration rate. Jama. 2012;307(18):1941-51.

27. Stevens L, Levey A. Frequently asked questions about GFR estimates. New York: National Kidney Foundation; 2004.

28. of the International, A.W.G., et al. The Oxford classification of IgA nephropathy: pathology definitions, correlations, and reproducibility. Kidney Int. 2009;76(5):546-56.

29. Tsuboi N, et al. Glomerular density in renal biopsy specimens predicts the longterm prognosis of IgA nephropathy. Clin J Am Soc Nephrol. 2010;5(1):39-44.

30. Fulladosa $X$, et al. Estimation of total glomerular number in stable renal transplants. J Am Soc Nephrol. 2003;14(10):2662-8.

31. Hughson MD, Samuel T, Hoy WE. Glomerular volume and clinicopathologic features related to disease severity in renal biopsies of African Americans and whites in the southeastern United States. Arch Pathol Lab Med. 2007; 131(11):1665.

32. Puelles VG, et al. Estimating individual glomerular volume in the human kidney: clinical perspectives. Nephrol Dial Transplant. 2012;27:1880-8.

33. Merlet-Bénichou $\mathrm{C}$, et al. Intrauterine growth retardation leads to a permanent nephron deficit in the rat. Pediatr Nephrol. 1994;8(2):175-80.

34. Hughson M, et al. Hypertension, glomerular number, and birth weight in African Americans and white subjects in the southeastern United States. Kidney Int. 2006;69(4):671-8

35. Keller $\mathrm{G}$, et al. Nephron number in patients with primary hypertension. N Engl J Med. 2003;348(2):101-8.

36. Keijzer-Veen $\mathrm{MG}$, et al. Microalbuminuria and lower glomerular filtration rate at young adult age in subjects born very premature and after intrauterine growth retardation. J Am Soc Nephrol. 2005;16(9):2762-8

37. Tsuboi $\mathrm{N}$, et al. Changes in the glomerular density and size in serial renal biopsies during the progression of IgA nephropathy. Nephrol Dial Transplant. 2009:24(3):892-9.

38. Ikezumi $Y$, et al. Low birthweight and premature birth are risk factors for podocytopenia and focal segmental glomerulosclerosis. Am J Nephrol. 2013;38(2):149-57

39. Ruggajo $P$, et al. Familial factors, low birth weight, and development of ESRD: a Nationwide registry study. Am J Kidney Dis. 2016;67(4):601-8.

40. Lemley KV, et al. Podocytopenia and disease severity in IgA nephropathy. Kidney Int. 2002;61(4):1475-85.

41. Wiggins R-C. The spectrum of podocytopathies: a unifying view of glomerular diseases. Kidney Int. 2007;71(12):1205-14.

42. Knoop T, et al. Mortality in patients with IgA nephropathy. Am J Kidney Dis. 2013;62(5):883-90.

43. Hannedouche T, et al. Factors affecting progression in advanced chronic renal failure. Clin Nephrol. 1993:39(6):312-20.

44. Ji H, et al. Female protection in progressive renal disease is associated with estradiol attenuation of superoxide production. Gender Med. 2007:4(1):56-71.

45. Silbiger SR, Neugarten J. The impact of gender on the progression of chronic renal disease. Am J Kidney Dis. 1995;25(4):515-33.

46. Woods $\mathrm{LL}$, Ingelfinger JR, Rasch R. Modest maternal protein restriction fails to program adult hypertension in female rats. Am J Phys Regul Integr Comp Phys. 2005;289(4):R1131-6. 
47. Xiao R, et al. Influence of pre-eclampsia on fetal growth. J Matern Fetal Neonatal Med. 2003;13(3):157-62

48. Lane PH, Steffes MW, Mauer SM. Estimation of glomerular volume: a comparison of four methods. Kidney Int. 1992:41(4):1085-9.

49. Basgen JM, et al. Comparison of methods for counting cells in the mouse glomerulus. Nephron Exp Nephrol. 2006;103(4):e139-48.

50. Samuel T, et al. Determinants of glomerular volume in different cortical zones of the human kidney. J Am Soc Nephrol. 2005;16(10):3102-9.

Ready to submit your research? Choose BMC and benefit from:

- fast, convenient online submission

- thorough peer review by experienced researchers in your field

- rapid publication on acceptance

- support for research data, including large and complex data types

- gold Open Access which fosters wider collaboration and increased citations

- maximum visibility for your research: over $100 \mathrm{M}$ website views per year

At $\mathrm{BMC}$, research is always in progress.

Learn more biomedcentral.com/submissions 